\title{
Diyarbakır ilinde Buğdayda Süne [Eurygaster integriceps Put. (Hemiptera: Scutelleridae)]'nin Popülasyon Dinamiği
}

\author{
Çetin Mutlu ${ }^{1 *}$, Vedat Karaca ${ }^{2}$, Mehmet Duman $^{3}$, Celalettin Gözüaçık ${ }^{4}$ \\ 1* Harran Üniversitesi, Ziraat Fakültesi, Bitki Koruma Bölümü, şanlıurfa, Türkiye, (ORCID: 0000-0003-4962-5506), cetinmutlu21@hotmail.com \\ 2 Zirai Mücadele Araştırma Enstitüsü, Diyarbakır, Türkiye (ORCID: 0000-0002-1144-047X), vedatkaraca@hotmail.com \\ ${ }^{3}$ Zirai Mücadele Araştırma Enstitüsü, Diyarbakır, Türkiye (ORCID: 0000-0003-4945-6757), mduman 53@hotmail.com \\ ${ }^{4}$ Iğdır Üniversitesi, Ziraat Fakültesi, Bitki Koruma Bölümü, Iğdır, Türkiye (ORCID: 0000-0002-6543-7663), cgozuacik46@gmail.com
}

(İlk Geliş Tarihi 4 Ekim 2021 ve Kabul Tarihi 13 Aralık 2021)

(DOI: 10.31590/ejosat.1004302)

ATIF/REFERENCE: Mutlu, Ç., Karaca, V., Duman, M. \& Gözüaçık, C. (2021). Diyarbakır ilinde Buğdayda Süne [Eurygaster integriceps Put. (Hemiptera: Scutelleridae)]'nin Popülasyon Dinamiği. Avrupa Bilim ve Teknoloji Dergisi, (31), 441-445.

\begin{abstract}
$\ddot{O} \mathbf{z}$
Buğday, insan beslenmesi için gerekli temel besinlerden biridir. Yoğun buğday üretimi yapılan Güneydoğu Anadolu Bölgesi 'nde Süne (Eurygaster integriceps Put.) halen ana zararlı durumundadır. Bu çalışma, Diyarbakır ilinde Süne'nin bazı ekmeklik ve makarnalık buğday çeşitlerindeki yıllara bağlı olarak kışlamış ergin (KE), nimf ve yeni nesil ergin (YNE) popülasyonunu ve buna göre uygun mücadele zamanını belirlemek amacıyla yapılmıştır. Çalışmalar, Diyarbakır ilinde 2004-2008 yılları arasında 9 farklı makarnalık ve ekmeklik buğday çeşidinde ve 20 farklı buğday tarlasında yürütülmüştür. Çalışma sonucunda Diyarbakır ilini çevreleyen kışlak alanlarından kışlakların boşalmasına bağlı olarak kışlamış süne ergin popülasyonun buğdayın sapa kalkma dönemi olan nisan ayının 3 . haftasında en üst seviyeye ulaştı̆̆ 1 ve bu tarihten sonra KE’lerdeki doğal ölümlerin başlamasıyla azalmaya başlayarak mayısın ikinci haftasında en alt seviyeye düştüğü belirlenmiştir. Süne nimflerinin buğdayın süt olum dönemi başlangıcı olan mayıs ayının ilk haftasında buğday başaklarında görülmeye ve bu dönemden sonra giderek artmaya başladığı belirlenmiştir. Buğday başaklarında sarı olum dönemi başlangıcı olan haziran ayının ilk haftasında ise nimf ve YNE ergin popülasyonun en üst seviyeye ulaştığı kaydedilmiştir. En fazla nimf yoğunluğu haziran ayının ilk haftasında Svevo (makarnalık) çeşidinde $114 \mathrm{nimf} / \mathrm{m} 2$ ile olurken en düşük yoğunluğun ise 4.3 nimf $/ \mathrm{m} 2$ ile Nurkent (ekmeklik) çeşidinde olduğu belirlenmiştr. Süne mücadelesinde zamanlamanın çok önemli olduğu göz önüne alındığında buğday üreticilerinin Diyarbakır ilinde mayıs ayından itibaren tarla içinde gözlem yaparak Süne nimf yoğunluğunu kontrol etmeleri ve ekonomik zarar eşiğini geçmesi halinde mücadele yapmaları gerekmektedir.
\end{abstract}

Anahtar Kelimeler: Süne, sürvey, buğday, popülasyon, mücadele, Diyarbakır.

\section{Population Dynamics of Sunn Pest [Eurygaster integriceps Put. (Hemiptera: Scutelleridae)] on Wheat in Diyarbakır Province, Turkey}

\begin{abstract}
Wheat is among the primary elements in human nutrition. Sunn pest (Eurygaster integriceps Put.) is still a significant pest in southeastern Anatolia region having intensive wheat production. This study determined the population dynamics of overwintered adults (OWA), nymph and new generation adults (NGA) of sunn pest on some bread and durum wheat varieties during different years in Diyarbakir province. Determining the management time based on population dynamics was the other major objective. The studies were conducted during 2004-2008 in 20 different experimental fields where 9 different bread and durum wheat verities were cultivated. The overwintered sunn pest adult population reached the highest-level during 3rd week of April, which is stem elongation phase of wheat crop. The population started to decline after 3rd week of April with the onset of natural deaths OWAs and reached the lowest level
\end{abstract}

*Sorumlu Yazar: cetinmutlu21@hotmail.com 
during second week of May. Sunn pest nymphs appeared in wheat spikes at the initiation of milking stage (first week of May) and nymph population gradually increased after this period. Nymphs and NGA population reached the highest level at physiological maturity of wheat (first week of June) in the spikes. The highest nymph density was observed on Svevo (durum) variety with $114 \mathrm{nymph} / \mathrm{m} 2$, while the lowest density was in recorded on Nurkent (bread) variety with 4.3 nymph $/ \mathrm{m} 2$. Considering that timing is critical in the control of sunn pest, wheat producers in Diyarbakır should monitor nymph density in the field (starting from May) and the management measures when pest is expected to exceed economic treshold.

Keywords: Sunn pest, monitoring, wheat, population, control, Diyarbakır.

\section{Giriş}

İnsan beslenmesi için gerekli temel besinlerden olan buğday, ülkemizde üretimi yapılan hububat ürünleri içerisinde gerek ekiliş ve gerekse üretim bakımından her zaman ilk sırada yer almıştır (TUİK, 2021). Ülkemizde yetişen diğer tarımsal ürünlerde olduğu gibi buğday üretimini olumsuz yönde etkileyen faktörlerden birisi de zararlı böceklerdir (Anonim, 2008). Söz konusu zararlı böceklerden Güneydoğu Anadolu Bölgesi'nde en önemlisi Süne (Eurygaster integriceps Put.)'dir (Yüksel, 1968; 1969; Kılıç ve ark., 1973; Anonim, 2008; Özkan ve Babaroğlu; Karaca ve ark., 2012a,b; Mutlu ve ark., 2016).

Süne zararlısı Güneydoğu Anadolu Bölgesinde 1950'li yılların başından beri periyodik olarak, Trakya ve Orta Anadolu Bölgesi'nde ise son yıllarda önemli epidemiler yaparak tahılların özellikle de buğdayın en önemli zararlısı durumuna geçmiştir (Canhilal ve ark., 2007; İslamoğlu ve Kornoşor, 2010, 2011; Gözüaçık ve Yiğit, 2013; Özkan ve Babaroğlu, 2015). Süne buğdayda gerek nicelik ve gerekse nitelik yönünden önemli ürün kayıpları meydana getirmekte, Süneye karşı gerekli mücadele önlemleri alınmadığı takdirde ise buğdayda kardeşlenme döneminde kurtboğazı, başaklanma döneminde akbaşak zararı ve en önemlisi buğday tanelerinde meydana getirdiği emgi zararı nedeniyle \%100'e varan oranlarda zarar oluşturabilmektedir (Lodos, 1961; Yüksel, 1968; 1969; Kılıç ve ark., 1973; Anonim, 2008; Dizlek ve İslamoğlu, 2010; Mutlu ve ark.,2014; Özkan ve Babaroğlu, 2015; Özkan ve ark., 2017).

Türkiye'de 1927'den beri Süne üzerine bilimsel çalışmalara, 1955 yılından itibaren de kimyasal mücadeleye başlanılmıştır. Bugüne kadar entegre mücadele anlayışı içerisinde yürütülen Süne mücadelesinde, mücadele zamanı ve mücadeleye karar verme kriterleri olarak, geçmiş yıllarda Güneydoğu Anadolu Bölgemizde yapılan araştırmalar sonucu ortaya konulan esaslar kullanılmaktadır (Yüksel, 1968; 1969; Kılıç ve ark.,1973; Dörtbudak, 1974; Şimşek, 1998; Mutlu ve ark., 2014). Fakat temel olarak alınan bu esaslar günümüzde buğday ıslah ve yetiştiriciliğindeki gelişmelerle, farklı ekolojik koşullara uyumlu, verimi yüksek, erkenci çeşitler ile teknolojik kalite özellikleri açısından oldukça iyi olan sertifikalı çeşitlerin ağırlıkta ekilmeye başlanması, bölgede sulanabilir hububat alanların artması, son yıllarda sıkça meydana gelen kuraklık ve benzeri etmenlerden dolayı süne mücadelesinin zamanı ve mücadele kriterlerinin yeniden gözden geçirilmesi ihtiyacını gündeme getirmiştir (Koçak, 2005; 2006; Duman ve ark., 2008; Mutlu ve ark., 2014).

Zararlı böceklerin mevsimsel veya fenolojik olarak takibinin yapılarak popülasyon yoğunluklarının en üst seviyelerinin belirlenmesi, zararlı böceklerle mücadelenin en temel yöntemlerinden biridir (Speight ve ark., 2008). Dolaysıyla zararlı popülasyonlarının yoğunluğu veya en yoğun olduğu dönemlerin yıllık ve kısa dönemli sezonluk tahmini, bu zararlılara karşı yapılacak olan mücadelede çiftçilere en etkili kontrol stratejileri uygulamaya yardımcı olan önemli etkenlerden biridir (Matsukura ve ark., 2011).

Bu çalışma ile Güneydoğu Anadolu Bölgesi'den en fazla hububat ekimi yapılan Diyarbakır ilinde yaygın ekimi yapılan bazı ekmeklik ve makarnalık buğday çeşitlerindeki Süne kışlamış ergin, nimf+YNE yoğunluğu ile popülasyon gelişiminin belirlenmesi ve buna bağlı olarak süne ile mücadelede uygun zaman diliminde hazırlık yapılarak daha etkin mücadele için gerekli zaman aralığının belirlenmesi amaçlanmıştır.

\section{Materyal ve Metot}

Çalışmanın ana materyalini Diyarbakır ilinde bulunan buğday tarlaları, buğday bitkisi, kışlamış ergin (KE), nimf ve yeni nesil erginler (YNE), 1/4 m²'lik demir çerçeve diğer malzemeler oluşturmuştur.

\subsection{Süne'nin farklı buğday çeşitleri üzerinde popülasyon yoğunluğunun belirlenmesi}

$\mathrm{Bu}$ çalışma, Diyarbakır ilinde Süne kışlamış erginlerinin kışlak alanlarından inişlerinin son bulduğu nisan ayı başından itibaren $\mathrm{m}^{2}$ 'de farklı kışlamış ergin yoğunluklarının bulunduğu dört farklı ilçede ve 20 farklı buğday buğday tarlasında yürütülmüştür (Tablo 1).

Tablo 1. Çalışma yapılan yerler ve buğday çeşitleri

\begin{tabular}{|l|l|l|l|}
\hline Y1l & İlçe & Buğday Çeşidi & Buğday Türü \\
\hline \multirow{4}{*}{2004} & Ergani & Bezostaja & Ekmeklik \\
\cline { 2 - 4 } & Ergani & Fırat 93 & Makarnalık \\
\cline { 2 - 4 } & Ergani & Svevo & Makarnalık \\
\cline { 2 - 4 } & Merkez & Dariel & Ekmeklik \\
\cline { 2 - 4 } & Merkez & Dariel & Ekmeklik \\
\hline 2005 & Çınar & Pehlivan & Ekmeklik \\
\cline { 2 - 4 } & Merkez & Svevo & Makarnalık \\
\hline \multirow{3}{*}{2006} & Merkez & Bezostaja & Ekmeklik \\
\cline { 2 - 4 } & Merkez & Pehlivan & Ekmeklik \\
\cline { 2 - 4 } & Hazro & Nurkent & Makmeklik \\
\hline \multirow{4}{*}{2007} & Çırnalık & Svevo \\
\cline { 2 - 4 } & Merkez & Cumhuriyet 75 & Ekmeklik \\
\cline { 2 - 4 } & Hazro & Basri Bey & Ekmeklik \\
\cline { 2 - 4 } & Hazro & Pehlivan & Ekmeklik \\
\cline { 2 - 4 } & Hazro & Nurkent & Ekmeklik \\
\hline & Hazro & Basribey & \\
\hline
\end{tabular}




\begin{tabular}{|l|l|l|l|}
\hline \multirow{3}{*}{2008} & Hazro & Cemre & Ekmeklik \\
\cline { 2 - 4 } & Hazro & Cumhuriyet 75 & Ekmeklik \\
\cline { 2 - 4 } & Hazro & Nurkent & Ekmeklik \\
\cline { 2 - 4 } & Hazro & Pehlivan & Ekmeklik \\
\hline
\end{tabular}

Kışlaklarda yapılan gözlemlerle birlikte, kışlaklardan tarlalara inişlerin son bulduğu tarihten hemen sonra farklı kışlamı̧ süne ergin yoğunluğuna sahip tarlalar deneme alanı olarak seçilmiştir. Çalışmalar en az 10 dekarlık buğday alanlarında Süne mücadelesinde kullanılan teknik talimat esaslarına göre (tarla büyüklüğü 1-20 dekar ve sayım adedi 12
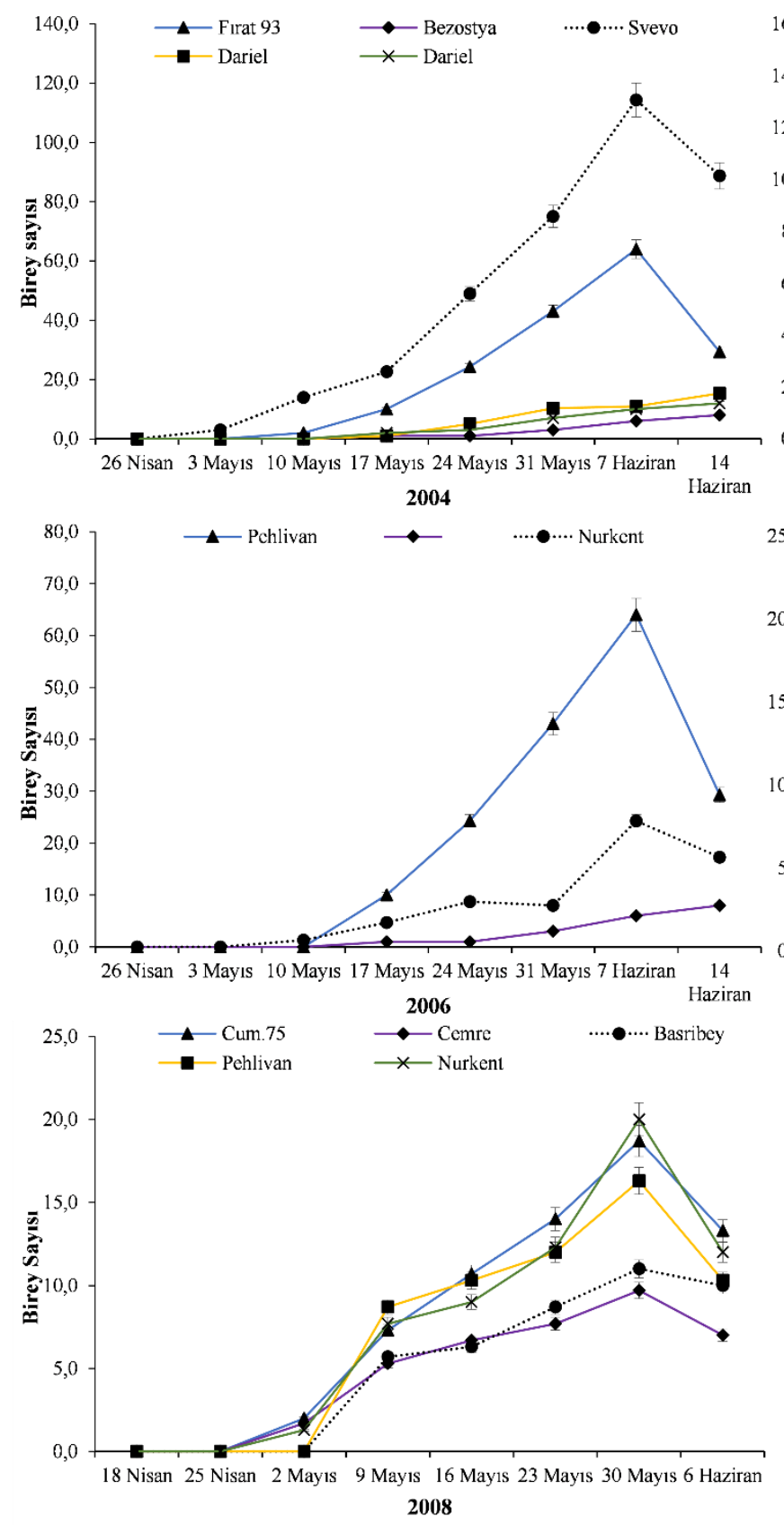

Şekil 1. Diyarbakır ili 2004-2008 yılları arasında farklı buğday çeşitlerinde Süne'nin popülasyon gelişimi ve yeni nesil erginler sayılarak kaydedilmiştir. 2005 2007

çerçeve) (Dörtbudak, 1979) yürütülerek kışlamış Süne ergin yoğunluğunu tespit etmek için sayımlar yapılmış ve çerçeve içerisine giren tüm birey sayısı değerlendirmeye alınmıştır.

Kışlamış süne ergin sayımları tamamlandıktan sonra bu alanlara hasada kadar birer hafta ara gidilerek süne nimf ve yeni nesil ergin yoğunluğunu belirlemek için deneme alanına rastgele $12 \mathrm{kez} 1 / 4 \mathrm{~m}^{2}$ lik demir çerçeve atılarak çerçeve içine giren nimf
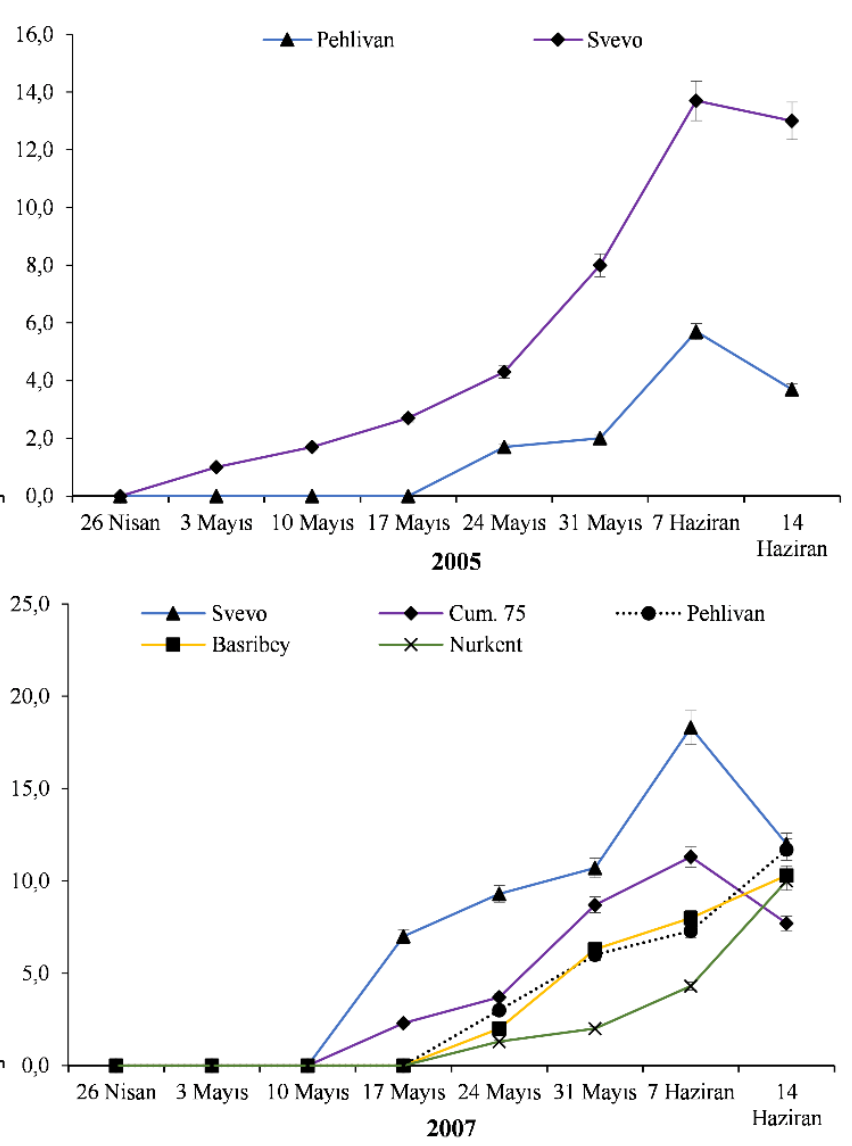


\section{Araştırma Sonuçları ve Tartışma}

\subsection{Süne'nin farklı buğday çeşitleri üzerinde popülasyon yoğunluğunun belirlenmesi}

Diyarbakır ili Merkez, Çınar, Ergani ve Hazro ilçelerinde kışlamış Süne ergin sayımlarına ait sonuçlar Tablo 2'de verilmiştir.

Çalışma yapılan beş yıllık süre boyunca, kışlaklardan süne inişlerinin tamamlandığı nisan ayı ortasına kadar (fenolojik dönem: buğdayın sapa kalkma dönemi) Basribey çeşidi hariç KE sayısının, süne mücadelesinde kıymetlendirme sürveyi için esas alınan $1 \mathrm{~m}^{2}$ 'de $0.8 \mathrm{KE}$ (Anonim, 2008) sayısının çok üzerinde olduğu belirlenmiştir. Kışlamış ergin süne sayısı en yüksek Svevo makarnalık çeşidinde $\left(1 \mathrm{~m}^{2}\right.$ 'de 3.7$)$ kaydedilmiş, en düşük ise Basribey ekmeklik çeşidinde $0.7 \mathrm{KE} / \mathrm{m}^{2}$ olarak belirlenmiştir. Çalışma yapılan yıllara göre belirlenen kışlamış süne ergin popülasyonu göreceli olarak nimf popülasyonunun artmasına neden olmuştur. Çalışmanın birinci yılı olan 2004 yılında KE poplasyonu ortalama $2.0 \mathrm{KE} / \mathrm{m}^{2}$ olarak belirlenmiş ve aynı yıl nimf popülasyonu ise ortalama $24.6 \mathrm{nimf} / \mathrm{m}^{2}$ olarak gerçekleşmiştir.

Sayım yapılan 2004-2008 yılları arasında, 2008 yılı hariç süne nimflerinin Diyarbakır ilinde mayıs ayının ikinci haftasından itibaren görülmeye başladığı (Şekil 1) ve bu dönemde buğday bitkisinin fenolojik olarak süt olum döneminde olduğu belirlenmiştir. Çalışmanın son yılı olan 2008 yılında kısmen kuraklık ve sıcaklıkların önceki yıllara göre daha yüksek olması nedeniyle önceki yıllara göre ilk nimfler mayıs ayının ilk haftasında belirlenmiştir (Şekil 1). Bu dönemden itibaren nimf ve YNE ergin yoğunluğunda artışlar meydana gelmiş ve 2008 yılı hariç diğer yıllarda haziran ayının ilk haftasında en üst seviyeye ulaşmıştır. Bu dönemde buğdayın sert olum dönemde olduğu kaydedilmiştir. Haziran ayının ikinci haftasında sıcaklık artışı ve nimflerin YNE olması nedeniyle meydana gelen kışlaklara göç nedeniyle popülasyonda keskin bir düşüş gözlenmiştir.

Tablo 2. Çalışma yapılan buğday çeşitlerindeki KE sayıları

\begin{tabular}{|c|l|c|}
\hline Y11 & Buğday çeşidi & Kişlamış Ergin Sayıs1 $\left(\mathrm{m}^{2}\right)$ \\
\hline \multirow{4}{*}{2004} & Bezostaja & 1.0 \\
\cline { 2 - 3 } & Firat 93 & 2.3 \\
\cline { 2 - 3 } & Svevo & 3.7 \\
\cline { 2 - 3 } & Dariel-1 & 2.0 \\
\cline { 2 - 3 } & Dariel-2 & 1.3 \\
\hline 2005 & Pehlivan & 1.0 \\
\cline { 2 - 3 } & Svevo & 1.7 \\
\hline \multirow{4}{*}{2006} & Bezostaja & 1.7 \\
\cline { 2 - 3 } & Pehlivan & 2.0 \\
\cline { 2 - 3 } & Nurkent & 1.3 \\
\hline \multirow{5}{*}{2007} & Cumhuriyet 75 & 1.7 \\
\cline { 2 - 3 } & Svevo & 1.7 \\
\cline { 2 - 3 } & Basribey & 1.0 \\
\cline { 2 - 3 } & Nurkent & 1.3 \\
\cline { 2 - 3 } & Pehlivan & 1.3 \\
\hline \multirow{5}{*}{2008} & Basribey & 0.7 \\
\cline { 2 - 3 } & Cemre & 1.0 \\
\cline { 2 - 3 } & Cumhuriyet 75 & 1.7 \\
\cline { 2 - 3 } & Nurkent & 1.7 \\
\cline { 2 - 3 } & Pehlivan & 2.0 \\
\hline
\end{tabular}

Süne nimf ve YNE ergin yoğunluklarına yıllara göre değişiklik göstermiş, en yüksek nimf+YNE yoğunluğu 2004 e-ISSN: 2148-2683 yılında (ortalama 114/ $\mathrm{m}^{2}$ ) olarak belirlenmiştir. Çalışma yapılan 2006 yilında bu rakam 86 nimf $+\mathrm{YNE} / \mathrm{m}^{2}$ olarak kaydedilmiştir. Buna rağmen popülasyon yoğunluğunun 2005, 2007 ve 2008 y1llarında ortalama $20 \mathrm{nimf}+\mathrm{YNE} / \mathrm{m}^{2}$ olarak ekonomik zarar eşiğinin üzerinde olduğu belirlenmiştir. Yüksel (1968), Güneydoğu Anadolu Bölgesinde yaptığı çalışmada 1. dönem süne nifmlerinin Floransa ve makarnalık buğdayda sapa kalkma ve başaklanma aşaması olan mayıs ayının 2. haftasından itibaren görüldüğünü ve Haziran'ın ilk haftasında 5. dönem nimflere akabinde yeni nesil erginlerin olduğunu bildirmiştir. Bu konuda Ankara ilinde yapılan bir diğer çalışmada Eurygaster maura L.'nın kışlaktan ovaya göç ettiği tarihlerde buğdayın sapa kalkma dönemi sonunda ve başaklanma dönemi başlangıcında olduğu bildirilmiştir (Memişoğlu (1992). Çalışmada elde edilen sonuçlara kısmen uymakla beraber Ege bölgesinde Derin ve ark. (1998), süne türlerinin kışlaklardan inişlerini tamamlandığı dönemde buğdayın kardeşlenmenin sonu ile sapa kalkma dönemi arasında olduğunu bildirmişlerdir.

\section{Sonuç}

$\mathrm{Bu}$ çalışma sonucunda, Diyarbakır ilinde aşırı iklim koşullarının (aşırı kuraklık ve sıcaklık olması vb.) meydana gelmemesi halinde Süne kışlamış erginlerinin kışlaklardaki kar örtüsü ve sıcaklığa bağlı olarak buğday alanlarında nisan ayı başında görüldüğü gözlenmiştir. Kışlamış ergin yoğunluğun Diyarbakır ili ve çevresinde nimf yoğunluğunu artıracak seviyenin üzerinde olduğu belirlenmiştir. Kışlamış erginlerden meydana gelen nimflerin ise ilçelerin bulunduğu coğrafik konum ve iklimsel koşullara bağlı olarak mayıs ayının ilk haftasından itibaren görülmeye başladığı ve bu tarihten sonra mücadele yapılmadığı takdirde Ekonomik Zarar Eşiği olan $10 \mathrm{nimf} / \mathrm{m}^{2}$ geçtiği belirlenmiştir. Son yıllarda gündemde olan küresel iklim değişiklikleri ile beraber sünenin kışlaklardan iniş tarihleri ile ovadaki popülasyonun takibinin yapılması ve buğday fenolojisi ile böceğin biyolojisinin tekrar ilişkilendirilmesi gerektiği düşünülmektedir.

Süne mücadelesinde zamanlamanın oluşabilecek ekonomik kayıpları önlemede çok önemli olduğu göz önüne alındığında; Diyarbakır ilinde buğday üreticilerinin, mayıs ayının ilk haftasından itibaren tarla içinde yeterli gözlem yaparak Süne nimf yoğunluğunu kontrol etmeleri ve ekonomik zarar eşiğinin aşılması durumunda mücadele yapmaları gerekmektedir.

\section{Kaynakça}

Anonim (2008). Gıda, Tarım ve Hayvancılık Bakanlığı, Zirai Mücadele Teknik Talimatları, Cilt 1. s.138.

Canhilal R., Kutuk H., İslamoglu M., Kanat A., Gul A. (2007). Damage Loss Assessment of Sunn Pest on Wheat in Turkey, Arab Society for Plant Protection, vol.1, pp.187-190

Derin, A., Kavut, H. (1998). Ege Bölgesindeki Süne çalışmaları. Süne Entegre Mücadele, 6-9 Ocak 1998, Ankara, 131-138.

Dizlek H., İslamoğlu M. (2010). Buğday Kitlesindeki Süne Emgi Oranlarının Belirlenmesinde Kullanılan Yöntemlerin Karşılaştırılması. U.Ü. Ziraat Fakültesi Dergisi, 24 (1):81- 90.

Dörtbudak Y., Koyuncu, N. (1979). Orta Anadolu'da Süne (Eurygaster spp.) türleri ve yoğunlukları üzerinde ön çalışmalar. Zirai Mücadele Araştırma Yı1lı̆̆g, 2-3.

Duman, M., Gözüaçik, C., Karaca, V., Mutlu, Ç. (2008). Süne mücadelesinde çiftçi davranışları: Adıyaman-Diyarbakır- 
Mardin-Şanlıurfa örneği, Harran Üniversitesi Ziraat Fakültesi Dergisi (12) 4: 65-71.

Gözüaçık, C., Yiğit, A. (2013). Süne, Eurygaster integriceps put. zararının bazı buğday çeşitlerinde kalite özelliklerine etkileri. Atatürk Üniversitesi Ziraat Fakültesi Dergisi, 44(2): 161-168.

İslamoğlu, M., Kornoşor S. (2010). Adıyaman Nemrut Kışlağında Farklı Kışlak Bitkilerinde Süne (Eurygaster integriceps Put.) Yoğunluğunun Parker Metoduna Göre Belirlenmesi. Ç.Ü. Fen Bilimleri Enstitüsü Dergisi, 23:1.

İslamoğlu M., Kornoşor S., Tarla Ş. (2011). Türkiye'de Süne, Eurygaster spp. (Hemiptera: Scutelleridae) Mücadelesindeki Gelişmeler (1928 - 2010). Türkiye Biyolojik Mücadele Dergisi, 2 (1): 63-78.

Karaca, V., Gözüaçık, C., Şimşek, Z. (2012a). Güneydoğu Anadolu Bölgesi'nde hububatın entomolojik sorunları ve çözüm önerileri. Türk Bilimsel Derlemeler Dergisi, 5 (2): 154 159.

Karaca, V., Gözüaçık, C., Şimşek, Z. (2012b). Süne (Eurygaster integriceps Put.) mücadelesinde havadan ilaçlamadan yönetimli çiftçi mücadelesine geçişin sürdürülebilir olması bakımından alınması gereken önlemler. Türk Bilimsel Derlemeler Dergisi, 5(2): 83-87.

Kılıç, A.U., Çatalpınar, A., Adıgüzel, N., Dörtbudak, Y. Çavdaroğlu.S. (1973). Güneydoğu Anadolu Bölgesinde Süne (Eurygaster integriceps Put.)' nin yayılışı, biyolojisi, ekolojisi, epidemiolojisi ile daha uygun kimyevi mücadele yöntemlerinin araştırılması. Proje nihai raporu, $121 \mathrm{~s}$.

Koçak, E. (2005). Güneydoğu Anadolu Bölgesinde süne (Euygaster integriceps Put.)'ninkışlamış ergin dönemine karşı kimyasal mücadele olanakları. IV: GAP Tarım Kongresi, 21 23 Eylül 2005, Şanlıurfa, 316-323.

Koçak, E. (2006). Süne Mücadelesinde zamanlamanın önemi, Türktarım, No:168, 42-45. Türkiye 3. Çayır-Mera ve Yem bitkileri Kongresi, 17-19 Haziran, Erzurum, s. 674-678.

Lodos, N. (1961). Türkiye, Irak, İran ve Suriye'de Süne (Eurygaster integriceps Put) problemi üzerinde incelemeler. Ege Üniversitesi Ziraat Fakültesi Yayınları, No:51,115s.

Matsukura, K., Yoshida, K., Matsumura, M. (2011). Efficient monitoring of maize orange leafhopper, Cicadulina bipunctata (Hemiptera: Cicadellidae), and small brown planthopper, Laodelphax striatellus (Hemiptera: Delphacidae), in forage maize fields using yellow sticky traps. Applied entomology and zoology, 46(4), 585-591.

Memişoğlu, H. (1985). Ankara ilinde süne türlerinin (Eurygaster spp.) (Hemiptera: Pentatomidae) yayılışları ve E. maura L.'nin biyo-ekolojisi ile savaş yöntemleri üzerinde araştırmalar.194s. (Yayınlanmamış doktora tezi).

Mutlu, Ç., Canhilal, C., Karaca, V., Duman, M., Gözüaçık, C. Kan, M. (2014). Economic threshold revision of the sunnpest (Eurygaster integriceps Put.) on wheat in Southeastern Anatolia Region. Türkiye Entomoloji Bülteni, 4(3): 157-169.

Mutlu, Ç., Duman, M., Karaca, V., Bayram, Y., Sıray, E., Kan, M. (2016). Kışlamış Süne Ergin Mücadelesinde Çiftçi Bilinç Düzeyi Örnek Çalışması: Güneydoğu Anadolu Bölgesi. Türk Tarım ve Doğa Bilimleri Dergisi, 3(4): 280-287.

Özkan, M., Babaroğlu, N.E. (2015). Süne. Gıda ve Kontrol Genel Müdürlüğü Yayınları, Ses Reklam İletişim ve Basım Hizmetleri, Ankara, $208 \mathrm{~s}$.

TUIK, 2021. Türkiye İstatistik Kurumu, Bitkisel üretim istatistikleri,

https://data.tuik.gov.tr/Kategori/GetKategori?p=tarim-

111\&dil=1 (Erişim tarihi: 01.10.2021).
Speight, M.R., Hunter, M.D., Watt, A.D. (2008) Insect pest management. In: Speight MR, Hunter MD, Watt AD (eds) Ecology of insects. Blackwell, Oxford, pp 429-513

Şimşek, Z. (1998). Türkiye'de süne (Eurygaster spp.) mücadelesinin genel durumu, dünü, bugünü. Entegre Süne Mücadelesi.I. Workshop Raporu.6-9 Ocak 1998.Ankara,165 s.(51-62s.).

Yüksel, M. (1968). Güney ve Güneydoğu Anadolu'da Süne (Eurygaster integriceps Put.)' nin yayılışı, biyolojisi, ekolojisi, epidemiolojisi ve zararı üzerinde araştırmalar. T.C. Tarım Bakanlığı Zirai Mücadele ve Karantina Genel Müdürlüğü Yayınları, No: 46 Teknik Bülten, Yenidesen Matbaası, Ankara, $255 \mathrm{~s}$.

Yüksel, M. (1969). Süne (Eurygaster integriceps Put.) zararı ve Kımıl (Aelia rostrata) zararıla mukayesesi üzerinde araştırmalar. Diyarbakır Bölge Zirai Mücadele Araştırma Ensitütüsü. Yeni desen Matbaası.1969.70 s. 